\title{
Artigo Original \\ I mplantação de um programa de avaliação terminal do desempenho dos graduandos para estimar a eficácia do currículo na Faculdade de Medicina de Ribeirão Preto
}

L.E. De A. Troncon, J .F. de C. Figueiredo, M. De L.V. Rodrigues, L.C. Peres, A.R.L. Cianflone, C.E. Picinato, M. DE F. A. Colares

Trabalho realizado pelo Grupo de Avaliação da Comissão de Graduação da Faculdade de Medicina de Ribeirão Preto - Universidade de São Paulo, Ribeirão Preto, SP.

RESUMO - Nos últi mos cinco anos, um programa de avaliação final do desempen ho dos graduandos vem sendo desenvolvido na Faculdade de Medicina de R i bei rão Preto, visando col her dados sobre a eficácia do currículo médico.

Овл етіvo. Descrever as principais etapas de implantação deste programa, bem como as medidas tomadas para superar as difi culdades encontradas.

MÉ todos. A avali ação consi ste em uma prova de conheci mentos e em exames práti cos de habilidades clínicas nas cinco áreas terminais do curso médico. As provas são elaboradas e aplicadas por docentes das ár eas envolvi das sob a supervisão de um grupo coordenador supra-departamental, que avalia todo o programa. Os graduandos participam como voluntários e os resultados são utilizados somente para os fins insti tucionais propostos. A adesão dos graduandos foi registrada e as impressões dos docentes e dos graduandos sobre o programa foram colhi das por meio de questionários específicos.

Resultados. Nos dois primeiros anos a adesão dos

\section{INTR ODUÇÃO}

A aval iação da eficácia do currículo degraduação constitui um procedimento pouco freqüente nas escolas médicas brasileiras e, quando realizada, baseia-se freqüentemente na percepção subjetiva dos alunos e professores ${ }^{1}$. Além disso, a avaliação do desempenho clínico dos graduandos, que tem sido crescentemente apontada como um fator da maior importância na $E$ ducação $M$ édica ${ }^{2,3}$, não é uma prática rotineira no Brasil ${ }^{4}$. A progressão dos estudantes ao l ongo das diferentes etapas do curso médico depende, quase exclusivamente, do bom aprovei tamento em provas vol tadas para os aspectos cognitivos. A avaliação das habilidades clínicas propriamente ditas, quando efetuada, baseia-se, em grande parte, nas impressões subjetivas dos preceptores dos estágios do I nternato e é freqüentemente desenvolvida de modo não-sistemático e sem definição de critérios objetivos.

Conseqüentemente, há uma escassez absoluta graduandos à prova de con hecimentos foi superior a $\mathbf{8 5 \%}$, mas o percentual de inscrições nas provas práticas foi de apenas $55 \%$. Além disso, do primei ro para o segundo ano, houve di mi nuição consi derável do grau de empen ho dos docentes envol vidos, obrigando medi das cor retivas voltadas ao recrutamento dos graduandos, à participação docente e aos métodos de avaliação prática. E m conseqüência, houve aumento notável da adesão dos estudantes queatingi u mais de $90 \%$ nos anos segui ntes. Houve, também, acréscimo considerável do empenho docente, o que garanti u adequado nível de qualidade à avaliação.

Conclusão. As medidas tomadas aumentaram a aceitação do programa e a qualidade das provas, permitindo que a avaliação do desempenho dos graduandos traga dados fidedignos sobrea eficácia do currículo.

UNITERMOS: Aval iação curricular. Avaliação dehabilidades clínicas. E studantes deM edi cina. E ducaçãomédica. Ensino médico. Planejamento e Avaliação Educacional.

de dados fundamentados sobre o padrão de desempenho clínico dos graduandos em Medi cina no Brasil, o que dificulta sobremanei ra a aval iação objetiva da eficácia geral do currículo.

$\mathrm{Na}$ F acul dade de M edicina de Ribei rão Preto (FM$\mathrm{RP}$ ), as discussões que vieram a resultar em ampla reforma curricular; trouxeram, também, a recomendação de se introduzir um sistema permanente de avaliaçãocurricular. A formação, no início de 1993, de um Grupo de Trabalho da Comissão de Graduação para implementar essa recomendação, seguiu-se da decisão de efetuar esta avaliação tendo como base o desempenho dos estudantes prestes a se graduarem. Deste modo, iniciou-se um esforço concentrado no sentido de criar condições objetivas para a realização desta avaliação, o que incluiu o recrutamento dos graduandos, a capacitação docente e a introdução de métodos mais objetivos de aval iação do desempenho clínico. O relato da experiência inicial da instituição com este tipo de trabalho foi apresentado anteriormente em publicação especifica ${ }^{5}$. 
Neste artigo apresenta-se uma descri ção global das principais etapas deste trabalho, desde o seu início até o presente momento, com ênfase nas dificul dades e resistênci as encontradas, bem como nas medi das tomadas para superá-las. Pretendeuse, ainda, dar uma idéia do estági o atual do processo e discutir as suas perspectivas futuras.

\section{MÉ TODOS}

\section{Características locais}

A FMRP é a unidade mais antiga do campus da Universidade deSão Paulo, localizado no interior do E stado. E ssa escol a médica admitia, atéa implantação de recenter eforma curricular, iniciada em 1992, 80 novos estudantes por ano e aproximadamente o mesmo número graduava-se ao final de cada ano.

O curso de medi cina é desenvolvi do em seis anos, divididos em um ciclo básico, um ciclo clínico e o I nternato em cinco áreas terminais: Clínica Médica, Pediatria e Puericultura, Cirurgia, Ortopedia e Traumatol ogia, Ginecol ogia e Obstetri ci a e M edicina Comunitária e Social.

U ma característica peculiar da instituiçãoéo fato de que mais de $80 \%$ do corpo docente, incluindo os professores dos departamentos clínicos, trabalha em regime de tempo integral e dedicação exclusiva à docência e à pesquisa. A grande maioria destes docentes é detentora de títulos de Mestrado e de Doutorado. Por outro lado, o interesse geral no ensino médico de graduação pode ser considerado como relativamente baixo, o que é indicado pel o fato da escola não possuir um setor de E ducação M édica ou um programa regular de capacitação e atualização de seus docentes em temas educacionais.

\section{A proposta original de avaliação}

Definiu-se, inicialmente, que toda a avaliação teria como base o elenco dos Objetivos Terminais do curso de graduação em Medicina, defini do pela instituição em $1987^{5}$. Para implementá-la, propôsse, or iginal mente, um programa composto por duas etapas, sendo a primeira constituída por uma prova de conhecimentos com base em testes de múltipla escolha; a segunda etapa era integrada por uma série de exames práticos específicos, vol tados para as habilidades clínicas, desenvol vidos com pacientes do Hospital das Clínicas da F MRP. Decidiu-se, desde o início, que a abrangência das provas cobriria somente as cinco áreas terminais do I nternato na FMRP. Os cinco departamentos envol vi dos indicaram, para trabal har sob a coordenação do Grupo de Trabalho responsável pela implantação do programa, 22 docentes escol hidos entre os que exercem suas funções na F acul dade em regi me de dedi-

\begin{tabular}{|c|c|c|}
\hline \multicolumn{3}{|c|}{$\begin{array}{l}\text { Tabela } 1 \text { - Avaliação terminal de competências do } \\
\text { graduandos da Faculdade de Medicina de Ribeirão Pretc } \\
\text { Número de estudantes prestes a se graduar em cada an } \\
\text { (elegíveis para a avaliação de competências) e de membro } \\
\text { do corpo docente participantes das atividades d } \\
\text { avaliação no período de } 1993 \text { a } 1996 \text {. }\end{array}$} \\
\hline Anos & Graduandos & Docentes \\
\hline 1993 & 82 & 22 \\
\hline 1994 & 80 & 27 \\
\hline 1995 & 83 & 16 \\
\hline 1996 & 84 & 18 \\
\hline
\end{tabular}

cação integral à docência e à pesquisa. A esses docentes foi designada a tarefa de desenvolver e aplicar os exames. Os integrantes do Grupo de Trabalho e os docentes indicados pelos Departamentos cumpriram, nos primeiros meses de 1993, um amplo programa de capacitação que incluiu lei turas sel eci onadas em ampl a revisão da literatura internacional sobre avaliação do desempenho clínico, bem como semi nários sobre aspectos gerais e específi cos da avaliação educacional, conduzi dos por especial istas da área de E ducação. Ao término deste programa, foram desenvolvidas em forma definitiva as provas a serem aplicadas, incluindo mais de uma centena de testes de múltipla escol ha e anteprojetos específicos para as provas práticas nas cinco áreas terminais já mencionadas.

Previu-se, inicialmente, aplicar as duas etapas de provas ao maior número possível dos 82 estudantes que deveriam graduar-se em 1993. Uma importante diretriz do programa era a de que as provas seriam aplicadas aos estudantes que decidissem inscrever-se vol untariamente para uma ou ambas as etapas da aval iação, com o compromisso de tratamento confidencial dos resultados e do seu emprego exclusivamente para os fins institucionais previstos. Ao mesmo tempo, desenvolveramse, ao longo dos primeiros meses daquele ano, atividades dirigidas à informação e ao recrutamento dos estudantes ${ }^{5}$.

\section{Receptividade dos estudantes e empenho dos docentes}

O número de estudantes prestes a se graduar em cada ano e de docentes partici pantes das atividades de avaliação no período de 1993 a 1996 são apresentados na Tabela 1.

A aceitação por parte dos graduandos foi estimada pelos porcentuais de inscrições nas diferentes etapas da aval iação em cada ano. Além disso, procurou-seidentificar fatores eventual menteresponsáveis pela baixa receptividade dos estudantes à proposta de avaliação. I sso foi feito pela aplicação prévia, a cada um dos estudantes el egíveis, de um questionário sobre sua disposi ção em se inscrever 


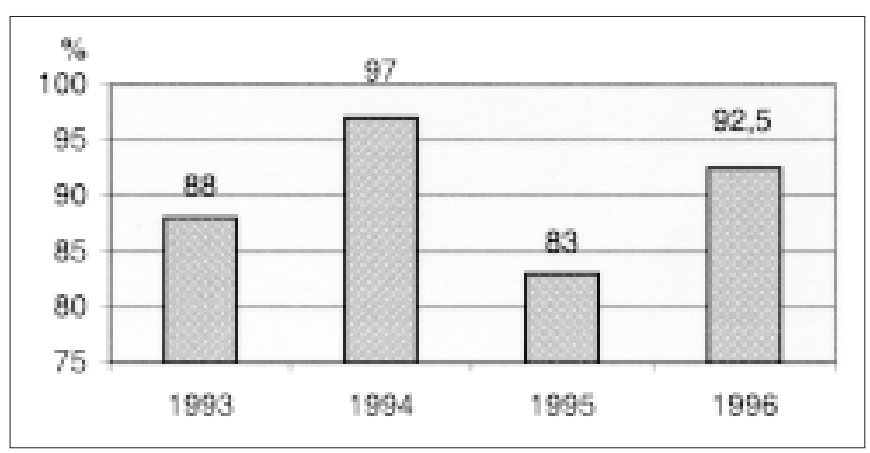

Fig. 1 - Porcentagem deadesãovol untária dos graduandos da F M RP à Prova deConheci mentos antes (1993 e 1994) e depois (1995 e 1996) das medi das cor retivas introduzi das pel o grupo coordenador da avaliação terminal .

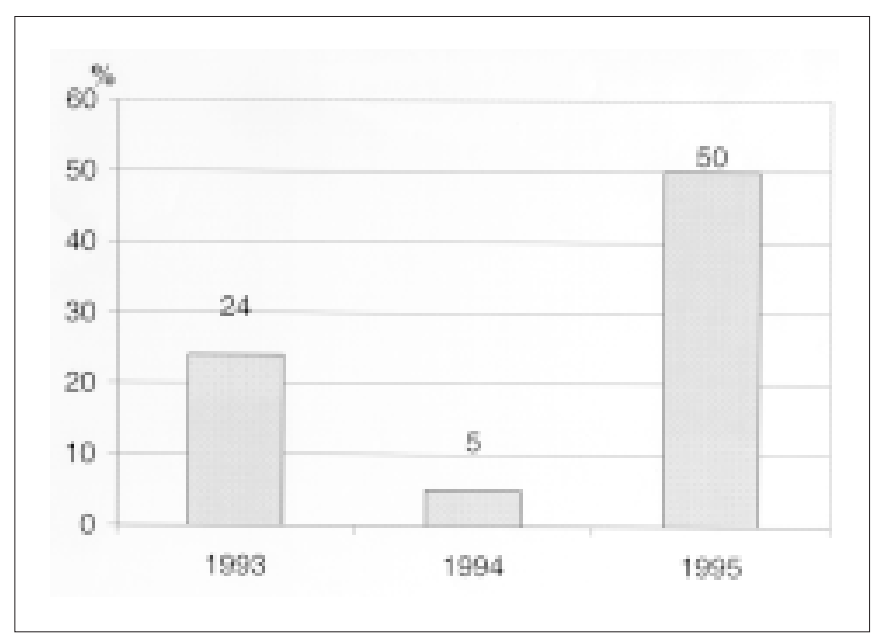

F ig. 3 - Porcentagem dos membros do corpo docente com escores el evados (4 e 5) em escala de 5 pontos de autoaval iação do grau de empenho nas atividades deavaliação, antes (1993 e 1994) e depois (1995) das medidas corretivas intriduzi das pel o grupo coor denador da avaliação terminal.

e as razões explicativas de eventual recusa. $\mathrm{Na}$ análise deste instrumento, foi dedicada atenção especial às respostas daquel es que não se inscreveram para as provas práticas.

O empenho dos docentes participantes do processo de aval iação foi esti mado mediante a aplicação, ao final de cada ano, de uma escala de anal ogia visual de cinco pontos (variando de 1 - mínimo a 5 - máximo) vol tada para a auto-avaliação do grau individual de envolvimento. Procurando identificar fatores eventualmente limitantes de maior envolvimento docente, todos os professores foram convidados a responder, junto com a aplicação da escala, a um questionári o contendo ítens rel ativos a fatores restritivos de maior empenho nas atividades de avaliação.

\section{Determinação de di fi culdades e indicação de medidas cor retivas}

A análise da receptividade dos graduandos e do

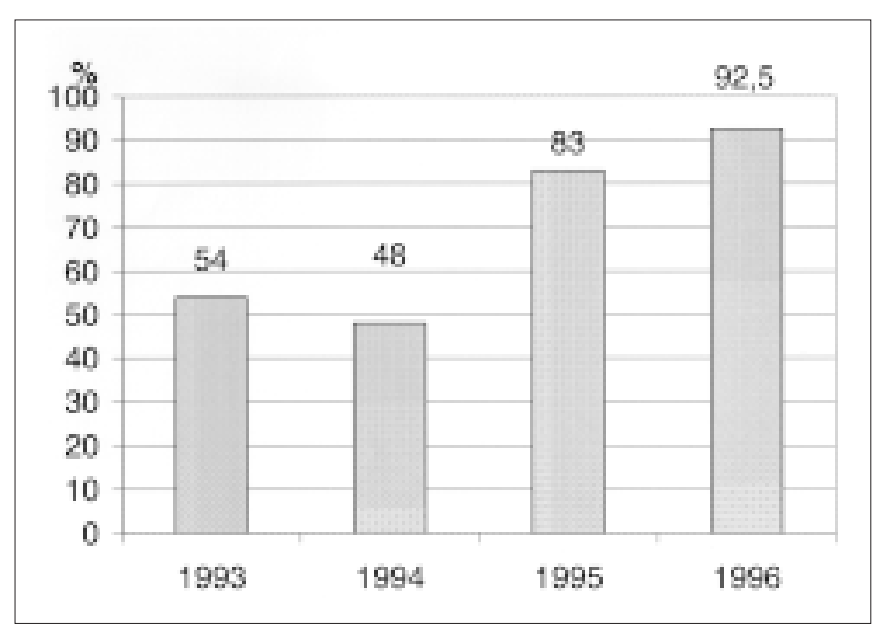

F ig. 2 - Porcentagem deadesão vol untária dos graduandos da F MRP às Provas de Práticas antes (1993 e 1994) e depoi s (1995 e 1996) das medi das corretivas introduzi das pelo grupo coordenador da aval iação termi nal.

grau de envolvimento dos docentes nos dois primeiros anos de implantação do programa permitiram identificar algumas dificuldades e a tomada de medidas específicas para superá-Ias. Essas medidas foram efetivamente implementadas em 1995 e mantidas em 1996. Além disso, o Grupo de Trabal ho coordenador do projeto de avaliação vem acompanhando cuidadosamente o desenvolvimento do mesmo, o que vem trazendo subsídios constantes para o seu aperfeiçoamento.

\section{RESULTADOS}

\section{Receptividade dos estudantes}

O percentual de adesão voluntária dos estudantes às etapas de avaliação de conhecimentos e de habilidades clínicas práticas nos quatro primeiros anos de implantação do proj eto são mostrados nas Figuras 1 e 2, respectivamente.

No primeiro ano de instalação do projeto, mais de 85\% dos estudantes concordaram em inscrever-se para a prova de conhecimentos, porém pouco mais de $50 \%$ del es apresentaram-se comovoluntári os para as provas práticas. No segundo ano, houve aumento da adesão à prova de conhecimentos, que se acompanhou de diminuição do percentual de estudantes que se inscreveram para as provas práticas.

O Quadro 1 apresenta as princi pais razões expl icitadas pelos estudantes para não se inscreverem para as provas práticas. A discordância em relação à modal idade somativa, com preferência por formas de avaliação contínua de cunho formativo, foi o fator mais freqüentemente apontado. Além disso, uma fração expressiva dos estudantes que não se inscreveram para as provas práticas, assinalou como razão explicativa deste comportamento, o 


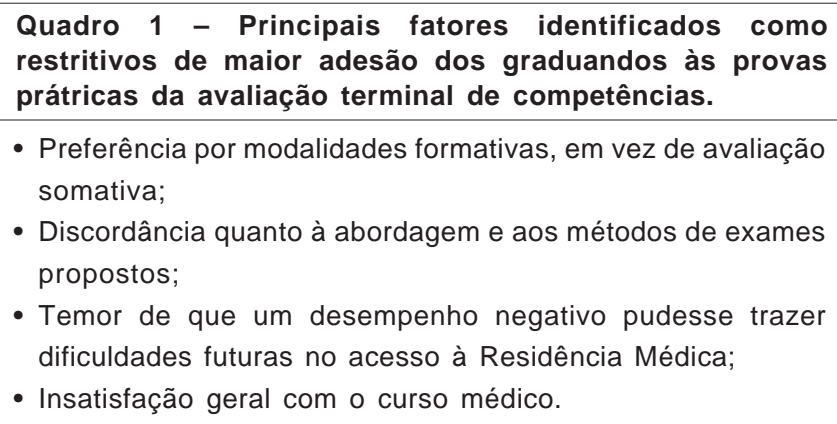
restritivos de maior adesão dos graduandos às provas prátricas da avaliação terminal de competências.

- Preferência por modalidades formativas, em vez de avaliação somativa;

- Discordância quanto à abordagem e aos métodos de exames propostos;

- Temor de que um desempenho negativo pudesse trazer dificuldades futuras no acesso à Residência Médica;

- Insatisfação geral com o curso médico.

temor de desempenho negativo, cuja detecção pudesse trazer conseqüências futuras em sua progressão na formação profissional .

\section{Comportamento do corpo docente}

O empenho inicial dos docentes foi considerado satisfatório, uma vez que cerca de $70 \%$ dos membros indi viduais tiveram escores iguais ou superiores a 3 na escala de empenho. No entanto, a proporção dos docentes com escores 4 e 5, indicativos de maior empenho, não foi muito grande e sofreu, ademais, decréscimo marcante do primeiro para o segundo ano, como mostra a Figura 3.

A aplicação do questionário destinado a identificar fatores limitantes indi cou que mais de $80 \%$ dos docentes reconhecia a falta de tempo, decorrente do acúmulo de atividades de ensino, pesquisa e de assistência médica, como impeditivas de maior envolvimento nas atividades do programa de avaliação terminal. Esta e outras razões, que foram reconhecidas pelos docentes como limitantes, são apresentadas no Quadro 2.

\section{Desenvolvimento das provas na etapa inicial}

No final do ano de 1993, algumas semanas antes do término do curso médico, os estudantes inscritos foram submetidos às duas etapas das provas previstas. A prova de Conhecimentos constou de 109 testes de múltipla escol ha abrangendo conteúdos das disciplinas das cinco áreas envolvidas. As provas Práticas foram realizadas em todas as cinco áreas, sendo que os Departamentos de Clínica Médica e de Medicina Social decidiram efetuar avaliação conjunta. Nessas duas áreas, bem como na de Ginecologia e Obstetrícia, optou-se por avaliar os alunos durante consultas ambulatoriais rotineiras. O mesmo foi feito pela área de Pediatria que, no entanto, ao invés de empregar avaliadores observando as consultas, optou por gravação em fita de vídeo, para posterior análise do desempenho dos graduandos. $\mathrm{Na}$ área de Cirurgia, foram realizadas provas específicas nas modal idades "casol ongo" e "casos curtos" ${ }^{\prime}$, com pacientes internados em E n-
Quadro 2 - Principais fatores indicados pelos docentes com limitantes ao maior envolvimento nas atividades do programa de avaliação terminal.

- Falta de tempo;

- Sobrecarga de atividades de ensino, pesquisa e assistência médica;

- Impressão de que as atividades educacionais são pouco valorizadas;

- Insegurança quanto à sua atuação como avaliador;

- Discordância quanto à abordagem e aos métodos de exames propostos.

fermarias. N essa área, as provas descritas foram compl ementadas por avali ação específica de habilidades cirúrgi cas necessárias em procedimentos de pequena monta, como suturas, dissecção de veias periféricas e introdução de sondas, feitos em animais anestesiados no L aboratório de Técnica Cirúrgica e Cirurgia Experimental. U m relato detalhado de todas as provas foi apresentado em publicação específica ${ }^{5}$.

E m 1994, realizou-se, pela segunda vez, a prova de Conhecimentos nos mesmos moldes do ano anterior. No entanto, o baixo grau de adesão dos graduandos, aliado à redução do empenho do corpo docente, inviabil izou a real ização das provas P ráticas. Estas foram efetivamente cumpridas em apenas duas das cinco áreas, com número mui to pequeno de estudantes.

\section{Impressões do Grupo Coordenador}

O acompanhamento da aplicação das provas práticas nos dois primeiros anos pelos integrantes do Grupo de Trabal ho coordenador do programa, permitiu detectar um númer o variado de imperfei ções. I sso gerou impressão da necessi dade de mel hora da qualidadegeral das mesmas. Percebeu-seal to grau de heterogenei dade entre as diferentes áreas nos protocolos de observação e no grau de adequação dos casos sel eci onados. Houve, ainda, fal ta de uniformidade em muitas das variáveis atinentes às provas, como o tempo concedido aos graduandos em cada situação de aval iação ou o grau de parti ci pação do examinador na referida situação. Ademais, constatou-se que propor ção considerável das habilidades que deveriam ser avaliadas não as foram, em função da falta de condições práticas apropriadas.

\section{Medidas corretivas}

A constatação das dificul dades mencionadas levou o Grupo Coordenador a repensar a proposta original de avaliação, com intenção de tomar medidas corr etivas. Os fatores possivel menter responsáveis pelas respostas dos estudantes e dos membros do corpo docente foram levados em consideração para a definição de várias medidas, que foram 


\begin{abstract}
Quadro 3 - Sumário do conteúdo das 10 estações constantes do módulo de Habilidades Clínicas, integrante das Provas Práticas em 1995 e 1996.

- Tomada de história clínica de adulto;

- Orientação a mãe de lactente com erro alimentar;

- Realização de teste de gravidez na urina e orientação a paciente sobre o resultado e medidas futuras;

- Interpretação de quadro clínico, foto de otoscopia e radiografias do tórax em criança com infecção respiratória;

- Exame físico geral em criança desnutrida;

- Exame do precórdio em adulto normal com palpitação;

- Exame do baço em paciente com equistossomose;

- Interpretação de diapositivos de alterações do exame abdominal e ginecológico (diagnóstico de inspecção em ginecologia e obstetrícia);

- Tomada de história clínica de mãe de criança com possível deficiência do desenvolvimento neuro-psico-motor;

Interpretação de radiografia do tórax e de eletrocardiograma de adulto com dor torácica.
\end{abstract}

efeti vamente implementadas a partir de 1995. Essas medidas constaram de mudanças:

1. No modo de inscrição dos estudantes voluntários às provas; ao invés deter a possi bili dadede opção por uma ou por ambas as etapas, os estudantes passaram a ter que se inscrever para toda a avaliação. Passaram, portanto, a ter que se submeter, necessariamente, à etapa de provas Práticas para terem a oportunidade de fazer a prova de Conhecimentos;

2. No modo de indicação dos membros do corpo docente encarregados das provas; ao invés de solicitar aos Departamentos, anualmente, a indicação de nomes, optou-se por convidar docentes com interesse, capacitação e disponibilidade para se envolverem ativamente no programa. Optou-se, portanto, em compor um el enco permanente de profissionais com as características adequadas ao trabalho necessário;

3. Na abrangência das provas Práticas; ao invés de efetuar as provas setoriais em cada uma das cinco áreas envolvidas, optou-se por realizar um conjunto menor de provas gerais. Estas, preparadas e conduzi das com mai or partici pação dos integrantes do Grupo de Trabalho coordenador do programa, passaram a incluir uma mistura de conhecimentos, habilidades e atitudes próprias das cinco áreas de abrangência da avaliação;

4. N os métodos aplicados na real ização das provas; ao invés de realizar as provas com métodos tradicionais de exame do desempenho clíni co ${ }^{5,6}$, passousea empregar métodos mais modernos e objetivos ${ }^{7}$, dotados, presumivelmente, de maior validade e fidedignidade 8 .

\section{Mudanças observadas}

Em resposta à implementação das mudanças propostas, houve um aumento considerável no percentual de estudantes participantes da avaliação, como mostram as Figuras 1 e 2. O exame conjunto destas duas figuras permite concluir que a mudança na sistemática de voluntariado dos graduandos trouxe um aumento marcante na proporção de estudantes disponíveis para a aplicação das provas Práticas, sem que tenha havido queda significativa na proporção de graduandos disponíveis para a prova de Conhecimentos.

A Figura 3 mostra que, no ano seguinte à apl i cação das medi das corr etivas acima descritas, a proporção de membros do corpo docente com escore indi cativos de mai or envol vi mento foi, também, consideravelmente mais alta que nos dois primeiros anos.

\section{Desenvolvi mento das provas na etapa atual}

A superação das resistências dos graduandos ao vol untariado para as provas Práticas e a possibilidade de constituição de um grupo mais coeso de docentes, com características mais propícias a um maior envolvimento no programa de avaliação, permitiram a adoção de um novo formato para as provas. Nos anos de 1995 e 1996 foi possível configurar três módulos de provas, desti nados, respecti vamente, à avaliação de: a) H abilidades Clínicas; b) Habilidades Psicomotoras para a Realização de Procedimentos, e c) Habilidades Cognitivas E speciais. A prova de Conhecimentos foi realizada nos moldes idênticos ao adotado na etapa inicial .

A prova de Conhecimentos vem sendo aplicada a todos os graduandos que se inscrevem como voluntários à avaliação. Para cada um dos três módulos de provas práticas, designam-se, por sorteio, grupos de 18 a 20 alunos.

Os dois primeiros módulos das provas práticas vêm sendo desenvolvidos pela técnica de "exame clínico objetivo estruturado por estações ${ }^{9,10 "}$. As habilidades clínicas vêm sendo avaliadas em uma sequência de 10 estações integradas por el enco de "pacientes padronizados", queinclui pacientes reais, adultos e crianças, bem como pacientes simulados. Um sumário das tarefas propostas aos graduandos neste módulo está apresentado no Quadro 3.

As habilidades psicomotoras vêm sendo avaliadas em sequência de seis estações integradas por manequins e por animal anestesiado, nas quais solicita-se o cumprimento das tarefas apresentadas no Quadro 4. As habilidades cognitivas especiais foram avaliadas por modificação da técnica denominada de pati ent management problem ${ }^{11}$. Nesta prova, apresenta-se um problema clínico, cujo desdobramento oferece a oportunidade de sol icitar tarefas e tomadas de decisão variadas, conforme sumarizado no Quadro 5. 


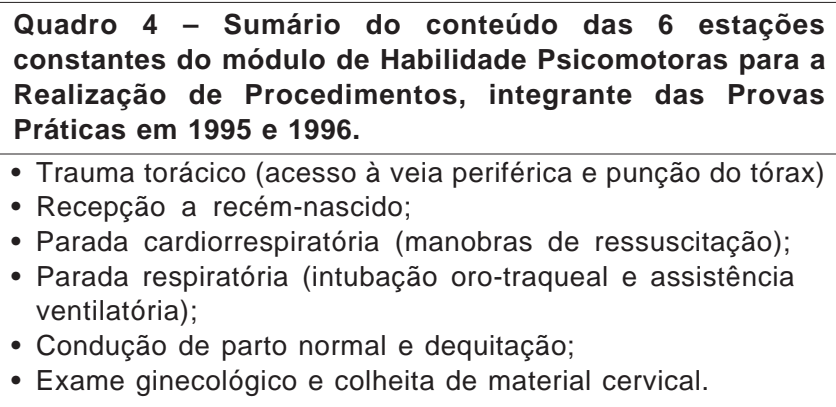
constantes do módulo de Habilidade Psicomotoras para a Realização de Procedimentos, integrante das Provas Práticas em 1995 e 1996.

- Trauma torácico (acesso à veia periférica e punção do tórax)

- Recepção a recém-nascido;

- Parada cardiorrespiratória (manobras de ressuscitação);

- Parada respiratória (intubação oro-traqueal e assistência ventilatória);

- Condução de parto normal e dequitação;

- Exame ginecológico e colheita de material cervical.

Quadro 5 - Sumário do conteúdo das etapas constantes da Prova de Habilidades Cognitivas Especiais, integrantes das Provas Práticas em 1995 e 1996.

- Análise da relevância de dados da história clínica;

- Análise da relevância de dados do exame físico;

- Proposição de hipóteses diagnósticas;

- Realização de prescição médica de admissão hospitalar;

- Indicação de exames complementares;

- Interpretação de exames laboratoriais;

- Interpretação de radiografias e eletrocardiograma;

- Revisão de hipóteses diagnósticas;

- Manejo de intercorrência;

- Análise de problema ético e médico legal;

- Preenchimento de atestado de óbito;

- Comunicação escrita: redação de ensaio curto.

\section{DISCUSSÃo}

A presente proposta de avaliação do currículo do curso médi co, por mei o da aferi ção do desempenho dos estudantes em vias de se graduar, além de original em nosso meio, constituiu-se, também, em uma oportunidade valiosa para observar alguns pontos rel ativos à atitude de estudantes e professores frente à aval iação educacional .

Com relação aos graduandos, notou-se, desde o início, franca aceitação da prova de Conhecimentos; no entanto, as observações efetuadas ao longo dos dois primei ros anos suger i ram que uma proporção considerável dos estudantes relutava em submeter-seà provas práticas, que parece ser vista por el es como uma experiência ameaçadora. I sso não é surpreendente, visto que a avaliação objetiva de habilidades clínicas psicomotoras e afetivas, ao nosso conhecimento, não é habitual mente conduzi da em nenhuma escola médica do País. Ademais, é reconhecida a ausência no sistema de ensino superior brasileiro de uma "cultura de aval iação $\mathrm{O}^{12} \mathrm{e}$ tanto estudantes como professores tendem a considerar os procedimentos de avaliação como algo destinado a "punir al guns estudantes e a premiar outros"13.

Do mesmo modo, a aceitação pronta da prova de Conhecimentos baseada em testes de múltipla escoIha pode ser explicada pelo fato de que, em todo o sistema educacional superior brasil ei ro, a aval iação do estudante é fortemente orientada para os aspectos de retenção de conhecimentos factuai $\mathrm{s}^{4,5,12}$. Além disso, uma análise cuidadosa do contexto local do ensino médico permite emprestar importância a um el emento chave, a saber, o processo de sel eção à Resi dência M édica, etapa seguinte, virtualmente obrigatória, da formação médica. É possível que este fator explique, em grande parte, a resposta dos graduandos às medidas corretivas tomadas em 1995, depois de constatadas as dificul dades para a impl ementação do programa.

A admissão à Residência M édica exige a aprovação em um concurso que consiste de uma etapa inicial, baseada em testes de múltipla escolha, seguida por entrevistas e análise do curriculum vitae dos candidatos. Esta fase é conduzida por docentes dos diferentes Departamentos. Desse modo, os graduandos aceitaram, em sua maioria, submeter-se à prova de Conhecimentos, que pode ter sido vista como uma "prévia" do concurso inicial de acesso à Residência. Do mesmo modo, os estudantes podem ter temido participar dos exames práticos porque as entrevistas da segunda fase do processo de seleção poderiam ser conduzidas por docentes que tivessem, eventualmente, testemunhado um desempenho insatisfatório.

Com as medidas corretivas tomadas em 1995, os graduandos tiveram que optar entre uma experiência potencialmente ameaçadora, a de se submeter às provas práticas, ou perder a oportunidade de se expor a uma situação potencialmente facilitadora do seu desempenho futuro na etapa inicial do acesso à Residência, submetendo-se à prova de Conhecimentos. Para neutralizar este dilema, algumas ações compensatórias foram, então, engendradas. Deum lado, procurou-se minimizar parte dos temores dos graduandos, ao se optar por incluir como avaliadores docentes convidados pel o Grupo coordenador, e não professores indicados pelos Departamentos envolvidos. Por outro lado, procurou-se implantar, na execução das provas práticas, métodos mais modernos e objetivos e, especialmente, menos dependentes da influência dos avaliadores, na avali ação do desempenho prático. I sso veio oferecer a oportunidade de aplicar, em escala mais ampla, métodos mais modernos, objetivos efidedignos de avaliação do desempenho clíni $\mathrm{Co}^{7,8,9,14}$, o que foi, em grande parte, facilitado pela experiência prévia disponível na instituição com o método de "exame clínico objetivo estruturado", com o emprego de pacientes padronizados ${ }^{10,11}$.

Ainda que o envolvimento inicial do corpo docente tivesse sido considerado como satisfatóri $0^{4}$, o prosseguimento do programa no ano seguinte veio associar-se à redução drástica do empenho indi vi- 
dual dos professores. A exploração deste ponto veio revelar um número de fatores limitantes à maior participação docente. É interessante mencionar que grande parte destes fatores são idênticos aos assinalados em um levantamento relativamente recente feito em grande número de escol as médicas da Améri ca do $\mathrm{N}_{\text {orte }} \mathrm{e}^{15}$, no qual identificou-sea falta de tempo e/ou de interesse como um dos principais óbices à introdução de inovações nos procedimentos de avaliação.

A substituição do sistema de indicação departamental por convites a professores com reconhecido interesse, disposição e disponibilidade para partici par de atividades mais genui namente educacionais, resultou, como seria de se esperar, em aumento notável no grau de empenho individual médio e permitiu a superação das dificuldades relacionadas ao corpo docente. Adicionalmente, esta medida permitiu a formação de um núcleo supra-departamental de professores de área clínica com adequada capacitação no emprego de métodos mais modernos de avaliação objetiva do desempenho clínico.

Apesar da existência das inúmeras dificuldades ora relatadas, a implementação do programa de avaliação terminal do desempenho dos graduandos, como meio de estimar a eficácia do currículo do curso médico na Faculdade de Medicina deRibeirão Preto foi factível e vem adquirindo o apoio de proporção substancial dos corpos discente e docenteda institui ção. A al ta qual ificação do cor po docente e, notadamente, o fato de que todos os professores envolvidos nas atividades de avaliação trabaI harem na Facul dade em regime de tempo integral e dedicação exclusiva à docência e à pesquisa, foram, indubitavel mente, fatores essenciais para o sucesso obtido.

A aplicação das diferentes provas nos anos de 1995 e 1996 nos mol des pretendidos em amostras representativas do perfil do graduando da instituição, permitiu que se obtivessem dados indicativos do desempenho dos estudantes em uma variedade de habilidades e competências importantes para a formação médica básica. A análise destes dados tem possibilitado o delineamento de um conjunto de pontos positivos e negativos do currículo do curso médico da F aculdade. Assim, será possível, em futurobreve, dispor de el ementos obj etivos para nortear eventuais mudanças e ajustes curriculares e acompanhar, nos anos subseqüentes, a eficiência das mudanças eventual mente introduzidas. Nesse sentido, um objetivo importante a ser preenchido pelo programa éa futura comparação do desempenho dos graduandos formados na antiga estrutura curricular com o daqueles formados a partir de 1998, queterão a sua formação baseada no novo currícul o da F MRP, implantado a partir de 1993.

Não é demais ressaltar que as informações obtidas na avaliação terminal referem-se não só ao domínio cognitivo, mas também às esferas das habilidades clínicas mais gerais, incluindo as de natureza psicomotora e afetiva.

Não obstante, reconhece-se a necessidade da introdução de mudanças contínuas no programa de avaliação, visando o seu aperfei çoamento global. Em especial, pretende-se ampliar o leque de habilidades e competências avaliadas, com a introdução nas difer entes provas de estações e etapas adi cionais com situações representati vas da prática médica cotidiana de nosso meio. Pretende-se, adicionalmente, introduzir, a partir de 1997, um método específico para a avaliação de atitudes, crenças e opiniões dos graduandos frente os diferentes aspectos rel evantes do exercício da profissão médica ${ }^{16}$.

Ao longo da aplicação das provas, foi possível notar a necessidade de fornecer, diretamente aos graduandos avaliados, informações imediatas sobre o seu desempenho. I sto vai possibilitar revestir a aval iação somati va de um caráter mais formativo, contribuindo, assim, di retamente, para a formação dos estudantes.

Por fim, a introdução do programa tem ensejado, no interior da institui ção, di scussões vivas sobre a necessidade de aperfei çoamento dos meios atualmente existentes de monitorização da qual idade do "produto" formado. Isto é justificado pela inexistência, no Estado e no País, de um sistema de verificação formal de competência médica, antes da autorização para exercício profissional pelas instâncias competentes. Desse modo, a proteção da soci edade contra médi cos inadequadamente habilitados ${ }^{17}$ recai sobre as insti tui ções formadoras e, em especial, sobre as escolas médicas.

E m conclusão, a introdução de um programa de avaliação mais objetiva do desempenho clínico dos graduandos em medi cina da nossa institui ção, possibilitou oreconhecimento de diferentes padrões de ati tudes de professores e de alunos frente à avaliação educacional. Esses padrões representaram dificuldades para a implementação do programa, que foram superadas com a tomada de medidas cor retivas apropriadas. Em particular, a introdução de métodos de mai or val idade efidedigni dade, concorreu para consolidar a acei tação do programa entre estudantes e professores. Conseqüentemente, a avaliação da eficácia do currículo do curso médico por meio do exame do desempenho clínico dos graduandos em Medicina passou a ser consi derada como uma proposta realista e factível. 


\section{AGRADECIMENTOS}

Os autores agradecem aos Professores Doutores Lisete Diniz Ribas Casagrande (Área de Educação, Departamento de Psicologia e Educação, Faculdade de Filosofia, Ciências e Letras, Campus de Ribeirão Preto da Universidade de São Paulo) e Heraldo Marelim Vianna (Fundação Carlos Chagas, São Paulo) pela assessoria prestada na fase inicial do projeto. Agradecem, também, aos Professores Doutores Eduardo Marcondes e Ernesto Lima Gonçalves (CEDEM - FMUSP), pela contribuição dada ao programa.

\section{SUMMARY}

\section{Summative assessment of medical student clinical performance for evaluation of cur- riculum efficacy.}

Purpose. To describethemain steps in theimplementation of such assessment, as well as to present the measures taken in order to overcome the difficulties that have been found.

Methods. Theproposed two-step assessment consists of a test of cognitiveaspects based on Multiple Choice Questions (MCQ) and practical exams of clinical skills in each of 5 terminal areas. Students enrolled as volunteer for either step or both. The examinations were devel oped and carried out by faculty members nomi nated by the invol ved Departments under the supervision of an institutional work group. Therates of student enrol Iment for the summative assessment has been recorded and the responses of both students and faculty members wereevaluated by means of specific questi onnaires.

RESULTS. I n the first two years, adhesion of students to the MCQ test was consistently high, but volunteering to the practical exams was persistentl y low. Moreover, therewas a sharp decrease in faculty involvement, from the first to the second year. To overcome these difficulties, a number of measures were implemented aiming at increasing student adhesion and faculty invol vement, as wel I as to improve assessment methods. As a consequence, a remarkable increase in both student adhesion and faculty invol vement was recorded.

ConCLUSION. Themeasures taken resul ted in sharp increases in both acceptance of the proposed assessment and the quality of the examination methods, which haveall owed a morer el iablecharacterization of the strenghts and weaknesses of the local curriculum. [Rev Ass Med Brasil 1999; 45(3): 217-24.]

KEY WORDS: Assessment, performance-based. Assessment of students. Assessment, clinical skills. Curriculum evaIuation. Undergraduate studies. Medical Education.

\section{REFERÊNCIAS BIBLIOGRÁFICAS}

1. Soares EC, Gualberto IC. Avaliação - Para que ? Revista Brasileira de Educação Médica 1990; 14: 11-16.

2. Lowry S. Assessment of students. British Medical J ournal 1993; 306: 51-54.

3. Mulholland H and Tombleson PMJ (1990). Assessment of the general practioner. British J ournal of General Practice 40, $252-254$.

4. Troncon LEA, Rodrigues MLV, Picinato CE, Cianflone ARL. Responses of students and faculty members to changes in assessment in a Brazilian medical school. In Rothman Al, Cohen R, editors. Proceedings of the Sixth Ottawa Conference on Medical Education, Toronto, University of Toronto Bookstore Custom Publishing Co., 1995; 120-122.

5. Troncon LEA, Cianflone ARL, Rodrigues MLV, Picinato CE, Peres LC, Figueiredo J FC. Avaliação terminal de competências clínicas dos graduandos em Medicina: relato da experiência inicial da Faculdade de Medicina de Ribeirão Preto. Faculdade de Medicina de Ribeirão Preto, 118 páginas, 1996.

6. Stokes J. The clinical examination: assessment of clinical skills. Medical Education Booklet Number 2. Association for the Study of Medical Education, Dundee, 1974.

7. Van Der Vleuten C, Newble DI. How can we test clinical reasoning. Lancet, 1995. 345: 1032-1034.

8. Van Der Vleuten CPM, Swanson DB. Assessment of clinical skills with standardized patients: State of the art. Teaching and Learning in Medicine 1990; 2: 58-76.

9. Harden RM, Gleeson FA. Assessment of clinical competence using an objective structured clinical examination (OSCE). Medical Education 1979; 13: 39-45.

10. Troncon LEA, F oss NT, Voltarelli J C, Dantas RO. Avaliação de habilidades clínicas por exame objetivo estruturado por estações, com emprego de paciente padronizados: descrição de dois métodos (Parte I). Rev Bras Educ Med, 1996. 20:45 - 52.

11. Harden RM. Preparation and presentation of patientmanagement problems (PMPs). Medical Education Booklet Number 17. Association for the Study of Medical Education, Dundee, 1983.

12. Vianna HM (1992). Avaliação E ducacional nos "Cadernos de Pesquisa". Cadernos de Pesquisa São Paulo 80, 100 - 105.

13. Krasilchik M (1992). Avaliação do Ensino. Faculdade de Educação da Universidade de São Paulo - Documentos Especiais 4, 6 - 11.

14. Troncon LEA, Foss NT, Voltarelli J C, Dantas RO. Avaliação de habilidades clínicas por exame objetivo estruturado por estações, com emprego de pacientes padronizados: uma aplicação no Brasil (Parte II). Rev Bras Educ Med, 1996. 20: $53-60$.

15. Swanson AG Brownell-Anderson M. Educating medical students. Academic Medicine (J une Supplement) 1993; S7-S46.

16. Gronlund WE. Measurement and evaluation in teaching. New York, McMillan Publishing Co., 1985.

17. McMannus IC. Examining the educated and the trained. Lancet 1995; 345: 1151-1153. 